\title{
Luminescence quenching by iron in barium aluminoborate glasses
}

\author{
Sheila Maria Del Nery \\ Faculdade de Engenharia de Guaratinguetá, Universidade Estadual Paulista “Júlio Mesquita Filho”, Guaratinguetá, SP, Brazil \\ Walter Maigon Pontuschka and Sadao Isotani \\ Instituto de Física Universidade de São Paulo, Caixa Postal 20516, 01498-970, São Paulo, SP, Brazil \\ Colin Graham Rouse \\ Instituto de Pesquisas Tecnológicas do Estado de São Paulo, Caixa Postal 7141, 05508 Cidade Universitária, São Paulo, SP, Brazil
}

(Received 8 March 1993; revised manuscript received 12 October 1993)

\begin{abstract}
The quenching of the radiative $e^{-}-h^{+}$recombination in barium aluminoborate glass, $x$ irradiated at $77 \mathrm{~K}$, was investigated by EPR and thermoluminescence (TL) techniques as a function of an iron impurity concentration ranging from $10^{-3}$ to 0.1 at. \%. The analysis of the EPR line shape of $\mathrm{Fe}^{3+}$, observed in these glasses, suggested that a large fraction of $\mathrm{Fe}$ impurity occupies substitutional sites of the glassforming network, locally charge compensated by a pair of $\mathrm{Ba}^{2+}$ interstitial cations. The electron untrapping activation energy from the boron electron centers [D. L. Griscom, J. Chem. Phys. 55, 1113 (1971)], obtained from the TL initial slope, is equal to $0.21 \mathrm{eV}$. The correlation between the TL intensity and the $\mathrm{Fe}$ concentration was found to be exponential, and is discussed on the basis of some recent theories for the nonradiative $e^{-}-h^{+}$recombination mechanism.
\end{abstract}

\section{INTRODUCTION}

The killing effect of luminescence produced by some impurities in crystals has been a subject of extensive studies. The first model of the competitive trapping ${ }^{2,3}$ of free electrons by two different centers of different emission wavelengths assumed a linear correlation between excitation intensity and luminescence. However, experiment has shown that the correlation is not always linear, ${ }^{4-7}$ so that excitation and recombination models with different carrier trapping cross sections ${ }^{8,9}$ were proposed. A killing effect of luminescence was observed also in chalcogenide glasses containing $\mathrm{Fe}^{2+}$ impurity. ${ }^{10}$ The process was explained as a nonradiative $e^{-}-h^{+}$recombination with a creation of an exciton strongly coupled with lattice phonons. In 1964, Gold and Weisberg ${ }^{11}$ introduced the role of the nonradiative recombination processes in order to explain the origin of the depletion zone enlargement at the $p-n$ junction which results in a time deterioration of the junction properties. This model assumed that the excitation energy acquired by the irradiated electron trapped at a deep level is released by means of a multiphonon emission or "phonon kick," which produces a very strong local heating. Sumi ${ }^{12}$ has proposed that the phonon kick is followed by a coherent hole trapping resulting in the creation of a very unstable exciton. He proposed a simple exponential law as a standard basis for the adiabatic limit for the electron transition, a process much faster than lattice motion.

Previous work ${ }^{13}$ on electron paramagnetic resonance (EPR) measurements of decay kinetics of boron-electron centers $(B E C)^{1}$ and review articles concerned with boron-oxygen hole centers ${ }^{14,15}$ (BOHC) between $77 \mathrm{~K}$ and room temperature have shown that the resulting blue thermoluminescence (TL) is a radiative $e^{-}-h^{+}$recombination between the electrons untrapped from the BEC and the self-trapped holes of BOHC [see Fig. 1(a)]. It was seen ${ }^{13}$ that at room temperature the BEC was virtually bleached, leaving an excess of BOHC's which needed additional heating to about $700 \mathrm{~K}$ for its complete bleaching. Another luminescence, of red color, appears at about $500 \mathrm{~K},{ }^{16}$ approximately the temperature of the complete bleaching of the last BOHC's, as observed by EPR. ${ }^{13}$ In order to explain the red luminescence observed at $500 \mathrm{~K}$ [see Fig. 1(b)], it was assumed that the imbalance of electrons and holes in the glass is due to $\mathrm{Fe}$ impurity. ${ }^{13}$

The possible charge-transport mechanisms which occur immediately after the thermal release from the carrier trapping site preceding the subsequent recombination are sketched schematically in Fig. 1. The solid lines assume a less probable possibility of the carrier to be promoted to the extended states by crossing the mobility edge. For the insulating glasses it is more likely that the entire process occurs inside the limits of the pseudogap (dashed lines), either by means of hopping or by direct charge-transfer process. However, such a detailed description is beyond the scope of the present paper.

The objective of this work is the study of the killing effect of $\mathrm{Fe}$ on the radiative $e^{-}-h^{+}$recombination in $\mathrm{x}-$ irradiated barium aluminoborate glasses, which occurs at temperatures between liquid-nitrogen temperature (LNT) and about $300 \mathrm{~K}$. The aim is to obtain a better understanding of the luminescence killing effect of Fe in amorphous materials. 


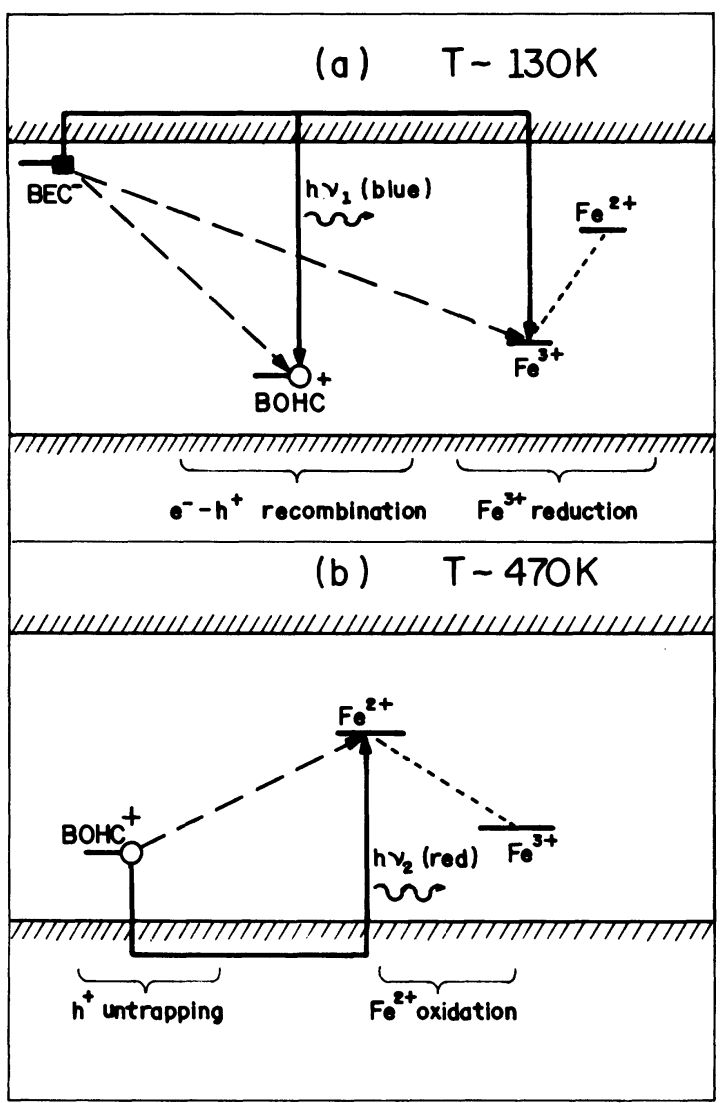

FIG. 1. (a) Electron-hole recombination mechanism of the blue TL emission in aluminoborate glasses $x$ irradiated at $77 \mathrm{~K}$ observed in the range of $80-310 \mathrm{~K}$. At these temperatures only the electrons of the BEC's can be released from their traps. In the sites where the $\mathrm{Fe}$ luminescence quenching action has not been reached, the holes cannot move at these relatively low temperatures. A small fraction of the released electrons may also be trapped by $\mathrm{Fe}^{3+}$ impurity ions. (b) Hole- $\mathrm{Fe}^{2+}$ recombination mechanism of the red TL emission in aluminoborate glasses $x$ irradiated at $77 \mathrm{~K}$ observed in the range of 380-650 K (Ref. 16). At these temperatures, the totality of the BEC's is bleached and the holes of the BOHC's acquire mobility until a $\mathrm{Fe}^{2+}$ ion is encountered which has originated from the $\mathrm{Fe}^{3+}$ ion previously reduced during the irradiation process.

\section{EXPERIMENTAL PROCEDURES}

The barium aluminoborate glass samples were prepared from a mixture of weighted amounts of reagent grade $\mathrm{Ba}(\mathrm{OH})_{2} \cdot 8 \mathrm{H}_{2} \mathrm{O}, \mathrm{H}_{3} \mathrm{BO}_{3}$, and $\mathrm{Al}_{2} \mathrm{O}_{3}$, melted in a platinum crucible at $1300^{\circ} \mathrm{C}$ for $2 \mathrm{~h}$ then annealed at $500^{\circ} \mathrm{C}$ and cooled to room temperature for $24 \mathrm{~h}$. Samples of $30 \mathrm{BaO} \cdot 50 \mathrm{~B}_{2} \mathrm{O}_{3} \cdot 20 \mathrm{Al}_{2} \mathrm{O}_{3}(\mathrm{~mol} \%)$ were prepared, containing controlled amounts of $\mathrm{Fe}$ impurity, added as $\mathrm{Fe}_{2} \mathrm{O}_{3}$ and $\mathrm{Fe}_{2} \mathrm{SO}_{4}$, as shown in Table $\mathrm{I}$. The sample denoted $E_{4}$ was melted by Bishay at the American University, Cairo, Egypt in alumina crucibles at $1340^{\circ} \mathrm{C}$ for $2 \frac{1}{2} \mathrm{~h}$ with composition $30 \mathrm{BaO} \cdot 60 \mathrm{~B}_{2} \mathrm{O}_{3} \cdot 10 \mathrm{Al}_{2} \mathrm{O}_{3}$. The samples were cut with dimensions of $2 \times 2 \times 6 \mathrm{~mm}^{3}$ for EPR and $1.5 \times 5 \times 10 \mathrm{~mm}^{3}$ for TL measurements.

The EPR spectra were obtained at room temperature
TABLE I. Area of EPR absorption at $g=4.3$ for given concentration of $\mathrm{Fe}^{3+}$.

\begin{tabular}{lccc}
\hline \hline & $\begin{array}{c}\text { Nominal } \\
\text { doping }\end{array}$ & $\begin{array}{c}\text { Area }^{\mathrm{b}} \\
\text { Sample }\end{array}$ & $\mathrm{Fe}$ (at. \%) \\
(arb units) $^{\mathrm{a}}$ & $N\left(10^{18}\right.$ spins $\left./ \mathrm{cm}^{3}\right)$ \\
$E_{0}$ & & $0.44 \pm 0.33$ & $1.13 \pm 0.08$ \\
$A_{3}$ & $1 \times 10^{-3}$ & $0.77 \pm 0.55$ & $2.1 \pm 0.2$ \\
$D_{3}$ & $2 \times 10^{-3}$ & $0.80 \pm 0.06$ & $2.9 \pm 0.2$ \\
$A_{2}$ & $1 \times 10^{-2}$ & $1.9 \pm 0.1$ & $4.8 \pm 0.3$ \\
$D_{2}$ & $2 \times 10^{-2}$ & $2.4 \pm 0.2$ & $6.1 \pm 0.6$ \\
$F_{2}$ & $4 \times 10^{-2}$ & $4.4 \pm 0.3$ & $11 \pm 0.8$ \\
$G_{2}$ & $2 \times 10^{-2}$ & $1.7 \pm 0.1$ & $4.3 \pm 0.3$ \\
$A_{1}$ & 0.1 & $5.9 \pm 0.4$ & $15 \pm 1$ \\
$B_{1}$ & 0.5 & $38 \pm 3$ & $96 \pm 9$ \\
$B_{2}$ & 0.8 & $61 \pm 4$ & $150 \pm 10$ \\
$E_{4}$ & & $0.45 \pm 0.003$ & $1.1 \pm 0.08$ \\
\hline \hline
\end{tabular}

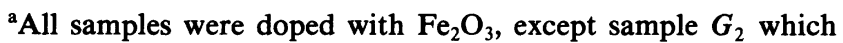
was doped with $\mathrm{Fe}_{2} \mathrm{SO}_{4}$.

${ }^{\mathrm{b}}$ Area under the EPR absorption curve.

using a homodine $\mathrm{x}$-band Bruker spectrometer. The TL measurements were carried out with an apparatus assembled in our laboratory. The temperature was controlled by a homemade cryostat at $1 \mathrm{mPa}\left(10^{-5}\right.$ torr) and measured with a Chromel-Alumel thermocouple. The TL light was directed through a glass window and detected by a Hamamatsu R910 photomultiplier and the signal was amplified by OP Intersil ICH8500/ACTV operational integrated circuit. Prior to the TL measurements, the samples were $x$ irradiated at LNT (Mo; $40 \mathrm{kV}$; $20 \mathrm{~mA}$ ) for $1 \mathrm{~h}$ of exposure. The optical absorption (OA) measurements were performed using a Carl-Zeiss DMR 21 spectrometer.

\section{EPR RESULTS}

The characteristic EPR lines ${ }^{17,18}$ of $\mathrm{Fe}^{3+}$ in the glassy matrix are easily identified. The resonance at $g=4.3$ is associated to the rhombic distortions of the local-order "crystal field" at a tetrahedral or octahedral site ${ }^{19}$ with $E / D \sim \frac{1}{3}$. The central Kramers doublet $\left(m_{s}=-\frac{1}{2}\right.$; $m_{s}=\frac{1}{2}$ ) produces a strong isotropic line at $g=4$.3. For the remaining two doublets the effective $g$ value is highly anisotropic, ranging from 1 to 10 , producing the largely spread background line with a shoulder appearing at $g=10$, which was attributed to interstitial $\mathrm{Fe}^{3+}$ ions (lattice modifiers). The $D$ values were estimated from the Aasa $^{20}$ diagram, which can assume every value between 1.5 and $3 \mathrm{~cm}^{-1}$.

Concentrations of $\mathrm{Fe}^{3+}$ in the glass samples were determined from the $g=4.3$ line by calculating the area under the absorption curve and normalizing for the mass and spectrometer amplification. For reference, samples $B_{1}$ and $B_{2}$ containing the larger amounts of $\mathrm{Fe}$ were prepared, where the nominal values are expected to be very close to the real concentrations. The relation between the areas of the $g=4.3$ lines of the samples $B_{1}$ and $B_{2}$ is 1.6 , as expected from the added concentrations of Fe. The error in the integration of the EPR signal was estimated to be about $7 \%$. The true concentrations of 
TABLE II. Correlation between the $\left[\mathrm{Fe}^{2+}\right]_{\mathrm{OA}} /\left[\mathrm{Fe}^{3+}\right]_{\mathrm{EPR}}$ value, normalized to the $B_{2}$ sample.

\begin{tabular}{|c|c|c|c|c|c|}
\hline Sample & $\begin{array}{l}\text { OA band } \\
\text { amplitude } \\
h \text { (arb units) }\end{array}$ & $\begin{array}{c}\text { FWHM } \\
\left(10^{3} \mathrm{~cm}^{-1}\right)\end{array}$ & $\begin{array}{l}\text { Sample } \\
\text { thickness } \\
d(\mathrm{~cm})\end{array}$ & $\begin{array}{c}N_{\left(\mathrm{Fe}^{3+}\right)_{\text {EPR }}} \\
\left(10^{18} \text { spins } / \mathrm{cm}^{3}\right)\end{array}$ & $\begin{array}{c}\text { Correlation } \\
{\left[\left(h / N_{\left(\mathrm{Fe}^{3+}\right)}\right) \times(150 / 3.78)\right]}\end{array}$ \\
\hline$A_{1}$ & 0.36 & 4.4 & 0.795 & 15 & 0.95 \\
\hline$B_{1}$ & 2.25 & 4.4 & 0.840 & 96 & 0.93 \\
\hline$B_{2}$ & 3.78 & 4.4 & 0.816 & 150 & 1.00 \\
\hline
\end{tabular}

$\mathrm{Fe}^{3+}$, as well as the nominal doping, are given in Table I. The nonintentional doping of $10^{-3}$ at. $\%\left(\sim 1.13 \times 10^{18}\right.$ spins $/ \mathrm{cm}^{3}$ ) is not negligible. The effect of $x$ irradiation of the $E_{4}$ sample is a monotonical decrease of the EPR Fe ${ }^{3+}$ signal as a function of exposure time. As the $\mathrm{x}$-irradiated exposure time for the purpose of TL measurements was only $1 \mathrm{~h}$, it is estimated that the decrease of $\left[\mathrm{Fe}^{3+}\right]$ is no more than $3 \%$.

Samples $D_{2}$ and $G_{2}$ were doped with the same concentrations of $\mathrm{Fe}$, except that in the former $\mathrm{Fe}^{3+}$ ions were added and in the latter, $\mathrm{Fe}^{2+}$. The $\mathrm{Fe}^{3+}$ EPR measurements detected a smaller signal for the $G_{2}$ sample, showing that the melting time $(2 \mathrm{~h})$ at $1300^{\circ} \mathrm{C}$ did not reach ferrous-ferric equilibrium in ordinary oxide glasses. In order to obtain the equilibrium, a longer time of about 20 $\mathrm{h}$ at $1400^{\circ} \mathrm{C}$ is necessary in an ordinary oxide glass. ${ }^{21}$

\section{OA RESULTS}

The OA absorbance curves in the range $4 \times 10^{3}$ $\mathrm{cm}^{-1}-27 \times 10^{3} \mathrm{~cm}^{-1}$ of the $A_{1}, B_{1}$, and $B_{2}$ samples containing $0.1,0.5$, and 0.8 at. $\%$ of $\mathrm{Fe}$, respectively, are shown in Fig. 2. The broadband having its maximum at $10 \times 10^{3} \mathrm{~cm}^{-1}$ is attributed to $\mathrm{Fe}^{2+}$ ions and the full width at half maximum (FWHM) for these three samples is equal to $4.4 \times 10^{3} \mathrm{~cm}^{-1}$. From Table II it is seen that the OA band amplitude $h$ is proportional to $\left[\mathrm{Fe}^{2+}\right.$ ], since the FWHM is constant, and $d$ is the sample thickness. Table II also shows that the correlation between the ratio

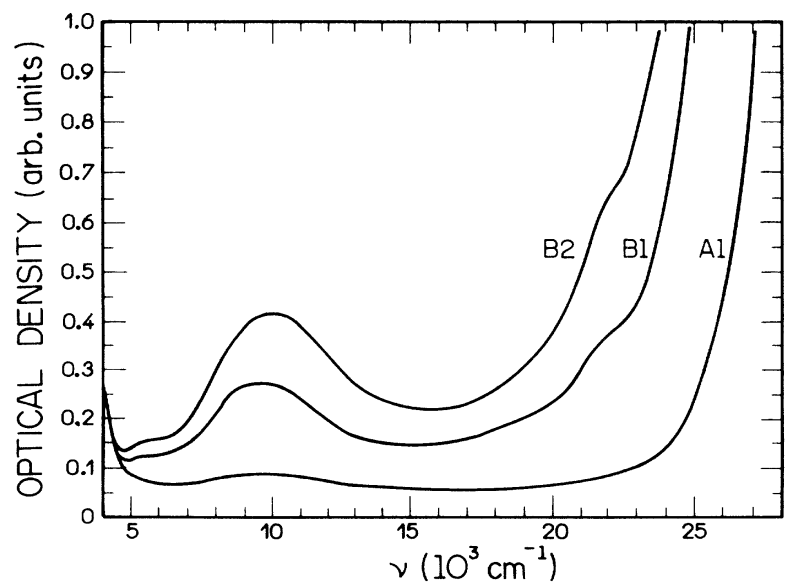

FIG. 2. Optical absorption spectra of the $A_{1}, B_{1}$, and $B_{2}$ samples, where the $10 \times 10^{3} \mathrm{~cm}^{-1}$ band is attributed to $\mathrm{Fe}^{2+}$. As the FWHM is constant, the band amplitude $h$ is proportional to $\left[\mathrm{Fe}^{2+}\right]$, which is correlated with $\left[\mathrm{Fe}^{3+}\right]$ from EPR measurements (see Table II).
$\left[\mathrm{Fe}^{2+}\right] /\left[\mathrm{Fe}^{3+}\right]$ and the $\mathrm{N}\left(\mathrm{Fe}^{3+}\right)$ value, measured by EPR, is constant in the range of $0.1-0.8$ at. \% of Fe doping levels. It is observed that (see Fig. 2) the $\mathrm{Fe}^{3+} \mathrm{UV}$ absorption band-tail displacement is towards lower energies in the visible with increasing $\mathrm{Fe}$ concentration.

\section{TL RESULTS}

TL emission of the samples $A_{2}, A_{3}, D_{2}, D_{3}, E_{0}, E_{4}$, $F_{2}$, and $G_{2}$ were observed in the temperature range of 77-300 K. The samples $A_{1}, B_{1}$, and $B_{2}$ did not exhibit any detectable luminescence. A typical TL curve obtained is shown in Fig. 3. The results were reproducible after successive procedures of annealing at $500^{\circ} \mathrm{C}$ for about $\frac{1}{2} \mathrm{~h}$, followed by a new $\mathrm{x}$ irradiation.

The activation energy of the TL process was determined for the samples $E_{0}$ and $E_{4}$ by the initial slope method. ${ }^{22}$ From the logarithmic plot versus $1 / T$ the activation energy was found as $(0.21 \pm 0.05) \mathrm{eV}$ for $E_{0}$ and $(0.22 \pm 0.05) \mathrm{eV}$ for $E_{4}$ sample. Therefore, the difference of 10 at. \% of the aluminum content in these samples did not affect sensitively the activation energy.

The areas under the TL curves are shown in Table III. Notice that the TL area decreases exponentially with the increase of the $\mathrm{Fe}^{3+}$ concentration (see Fig. 4).

The TL intensity of $E_{4}$ is about $\frac{1}{4}$ of the value observed in sample $E_{0}$, both having equivalent concentration of nonintentional $\mathrm{Fe}^{3+}$ impurity. The difference between

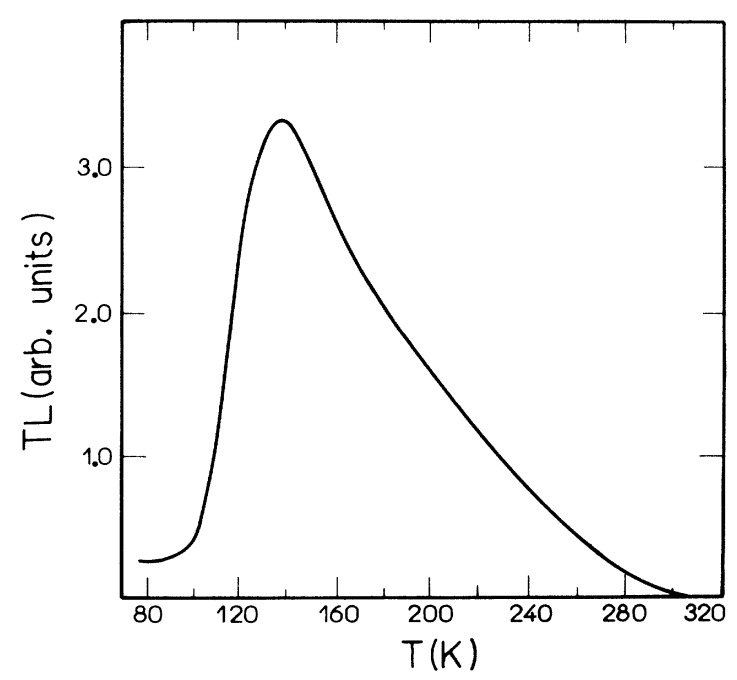

FIG. 3. TL curve of glass sample $A_{3}$ obtained between the temperatures of 77 and $300 \mathrm{~K}$. 
TABLE III. TL emission quenched by different concentrations of $\mathrm{Fe}^{3+}$ and $\mathrm{Fe}^{2+}$.

\begin{tabular}{lcccccc}
\hline \hline Sample & $\begin{array}{c}{\left[\mathrm{Fe}^{3+}\right]} \\
\left(10^{18} \text { spins } / \mathrm{cm}^{3}\right)\end{array}$ & $\begin{array}{c}{\left[\mathrm{Fe}^{2+}\right]} \\
\left(10^{17} \text { ions/cm }\right.\end{array}$ & $\begin{array}{c}A^{\mathrm{a}} \\
\text { (arb units) }\end{array}$ & $\begin{array}{c}A^{\mathrm{b}} \\
\text { (arb units) }\end{array}$ & $\begin{array}{c}\mathrm{TL} \\
\text { (arb units) }\end{array}$ & $\begin{array}{c}{\left[\mathrm{Fe}^{2+}\right] /\left[\mathrm{Fe}_{\text {total }}\right]} \\
(\%)\end{array}$ \\
\hline$E_{0}$ & $1.13 \pm 0.08$ & $0.60 \pm 0.04$ & 33.3 & 33.2 & $37.0 \pm 0.5$ & 5 \\
$A_{3}$ & $2.1 \pm 0.2$ & $1.1 \pm 0.1$ & 25.0 & 25.0 & $25.7 \pm 0.5$ & 5 \\
$D_{3}$ & $2.9 \pm 0.2$ & $1.5 \pm 0.1$ & 19.8 & 19.8 & $19.0 \pm 0.5$ & 5 \\
$G_{2}$ & $4.3 \pm 0.3$ & $21 \pm 1$ & 13.1 & 4.1 & $4.1 \pm 0.5$ & 33 \\
$A_{2}$ & $4.8 \pm 0.3$ & $2.5 \pm 0.2$ & 11.3 & 11.3 & $12.0 \pm 0.5$ & 5 \\
$D_{2}$ & $6.1 \pm 0.6$ & $3.2 \pm 0.3$ & 7.8 & 7.8 & $6.3 \pm 0.5$ & 5 \\
$F_{2}$ & $11 \pm 0.8$ & $5.8 \pm 0.4$ & 1.8 & 1.8 & $1.9 \pm 0.5$ & 5 \\
\hline \hline
\end{tabular}

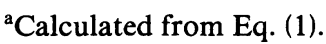

${ }^{\mathrm{b}}$ Calculated from Eq. (3).

the TL of these samples is due probably to the difference in the glass compositions and melting conditions.

Among the TL of the samples $D_{2}$ and $G_{2}$, described above, a slightly larger area was found for $D_{2}$, richer in $\mathrm{Fe}^{3+}$ within the limit of the experimental error. The reported killing effect of photoluminescence (PL) in chalcogenide glasses ${ }^{10}$ due to $\mathrm{Fe}^{2+}$ ions suggest that the remaining ferrous ions in aluminoborate glasses are also effective in the TL quenching in the present experiment.

The dependence of the TL area on the concentration $\left[\mathrm{Fe}^{3+}\right]$ is adjustable to an exponential law:

$A^{*}=46.3 \exp \left\{-2.93 \times 10^{-19}\left(\mathrm{~cm}^{3} /\right.\right.$ ion $\left.)\left[\mathrm{Fe}^{3+}\right]\right\}$,

where $A^{*}$ is the calculated area under the TL curve in arbitrary units and $\left[\mathrm{Fe}^{3+}\right]$ is given in units of $10^{18}$ ion $/ \mathrm{cm}^{3}$. The results are listed in Table III. It will be seen later that this expression can be identified with the exponential term which appears in the Sumi ${ }^{12}$ model.

\section{DISCUSSIONS}

As the interstitial $\mathrm{Fe}^{3+}$ ions do not contribute to the EPR line at $g=4.3,{ }^{17}$ we are concerned mainly with the substitutional sites in the glass-forming network.

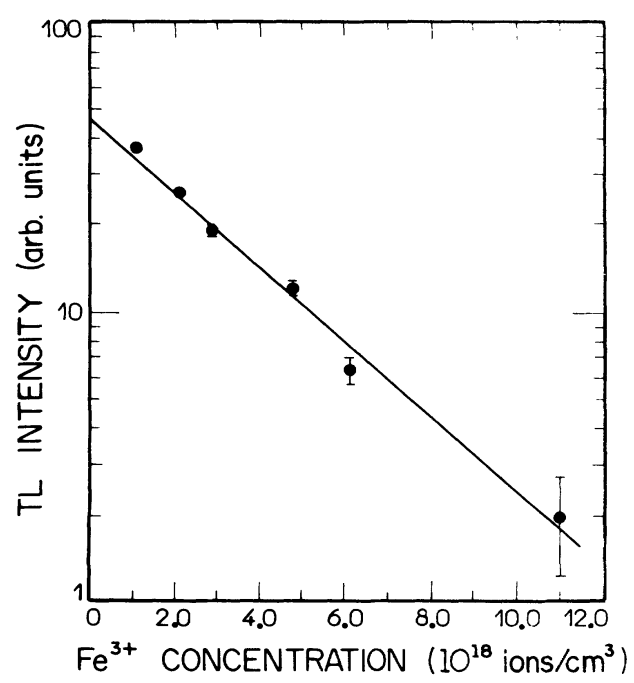

FIG. 4. Relation between the TL intensity and $\mathrm{Fe}^{3+}$ concentration.
The $\mathrm{Ba}^{2+}$ single ion alone is expected to produce a local field with axial symmetry, which should produce a $g=6$ line (or shoulder), not observed in the spectrum. There is no way for the single $\mathrm{Ba}^{2+}$ ion to produce a local electric-field symmetry which could generate the observed strong $g=4.3$ line. Only the attraction of a second positive ion produces the necessary condition for the $g=4.3$ site. $^{17}$

Another point which should be considered is that in alkali-earth borate glasses the double-tetrahedral $\mathrm{B}_{2} \mathrm{O}_{7}$ structure, charge compensated by a bivalent ion, has lower formation energy. ${ }^{23}$ Thus, there are two most probable local structures likely to occur as the $\mathrm{Fe}^{3+}$ site, satisfying conditions stated above:

(a) the double-tetrahedron $\mathrm{FeBO}_{7}$ containing two nonbridging oxygens (NBO) and charge compensated by a pair of $\mathrm{Ba}^{2+}$ ions [see Fig. 5(a)];

(b) a $\mathrm{FeO}_{6}$ octahedron entwined with a $\mathrm{BO}_{4}$ tetrahedron $\mathrm{FeBO}_{9}$, where all the oxygens are bridging (BO) and the charge compensation is again performed by a pair of $\mathrm{Ba}^{2+}$ ions [see Fig. 5(b)].

Both of these $\mathrm{Fe}^{3+}$ sites can be considered as "substitutional," even though the boron never appears inside an octahedral structure. Therefore, let us denote as "interstitial" only those $\mathrm{Fe}^{2+}$ or $\mathrm{Fe}^{3+}$ ions attracted near a negatively charged glass-forming structural unit for local charge compensation. Thus, the "substitutional" $\mathrm{Fe}^{3+}$ ion is subjected to a strong interaction between its external orbitals and the $p$ orbitals of the neighboring oxygens producing a molecular orbital. ${ }^{24}$ Remembering that the minimum ratio for the ionic radii of a cation to be tetracoordinated is 0.19 and hexacoordinated is 0.414 , it is expected from the following ratios of cation-oxygen radii of $0.51\left(\mathrm{Fe}^{3+}\right) ; 0.63\left(\mathrm{Fe}^{2+}\right)$, and $0.43\left(\mathrm{Al}^{3+}\right)$ that they all be hexacoordinated, but the tetrahedral site is more difficult for occupancy by $\mathrm{Fe}^{2+}$. Therefore, the $\mathrm{Fe}^{2+}$ ions are expected to be found more likely only in octahedral or interstitial positions.

The most part of $\mathrm{Fe}$ ions in the barium aluminoborate glasses appear as $\mathrm{Fe}^{3+}$ with only a negligible amount, less than $5 \%$ of the total $\mathrm{Fe}^{25,26}$ of remaining $\mathrm{Fe}^{2+}$ ions. To our knowledge, nothing about $\mathrm{Fe}^{4+}$ ions in these glasses has been reported. The appearance of such hypothetical $\mathrm{Fe}^{4+}$ ions would occur only at the expense of BOHC's, not confirmed by EPR. As the $x$ irradiation of $8 \mathrm{~h}$ of exposure produces a decrease of about $27 \%$ of the $\mathrm{Fe}^{3+}$ 

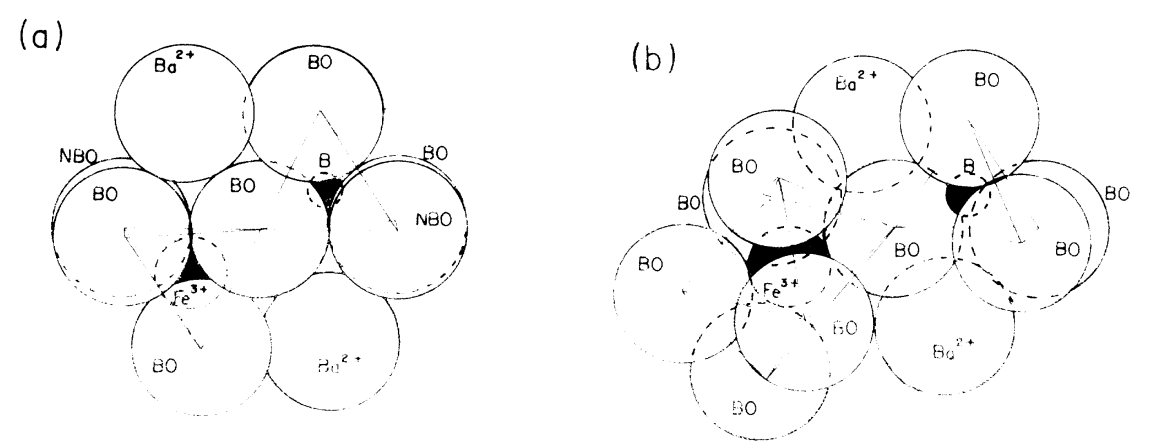

FIG. 5. (a) Double-tetrahedral $\mathrm{FeBO}_{7}$ structure containing two nonbriding oxygens (NBO) charge compensated by a pair of $\mathrm{Ba}^{2+}$ ions; (b) a structure composed of a $\mathrm{FeO}_{6}$ octahedron entwined with a $\mathrm{BO}_{4}$ tetrahedron $\left(\mathrm{FeBO}_{9}\right)$, where all of the oxygens are bridging (BO) and the charge compensation is again performed by a pair of $\mathrm{Ba}^{2+}$ ions.

EPR signal intensity at $g=4.3$, it follows that with a favorable local configuration such as described above, it is possible for the charge-compensated $\mathrm{Fe}^{3+}$ ion to trap a photoelectron thus creating a nonparamagnetic $\mathrm{Fe}^{2+}$ ion constituting a local negatively charged center. When the irradiated sample is heated from 77 to $300 \mathrm{~K}$, the totality of the electrons stored in BEC is released recombining with holes with the emission of a blue phosphorescence [see Fig. 1(a)], although a remaining number of holes still continue to be present in their traps of BOHC's. ${ }^{14}$ Assuming that their counterpart electrons were trapped by a small fraction of $\mathrm{Fe}^{3+}$ ions (a negligible amount for $1 \mathrm{~h}$ of $\mathrm{x}$ irradiation), their recombination does not occur before the complete $\mathrm{BOHC}$ bleaching at $400^{\circ} \mathrm{C}$, which is consistent with the appearance of a red TL emission observed at the same range of temperature. ${ }^{13,16}$

The $e^{-}-h^{+}$recombination blue TL emission is completely killed at $\mathrm{Fe}^{3+}$ doping concentrations above 0.1 at. \%. Assuming that the $\mathrm{Fe}^{3+}$ ions are uniformly distributed through the sample and that each $\mathrm{Fe}^{3+}$ ion is a TL killer, the effective volume of killing was evaluated as $V_{\mathrm{Fe}}=6.7 \times 10^{-2} \mathrm{~cm}^{3}$, which corresponds roughly to a radius of action of $25 \AA$. The fraction of tetrahedral $\mathrm{BO}_{4}$ units for the present molar fraction of $\mathrm{BaO}$ was calculated as 0.36 using the expression derived by Beekenkamp, ${ }^{23}$

$$
N_{4}=[x /(1-x)][1+\exp (10.85 x-5.0)]^{-1},
$$

where $x$ is the molar fraction of the alkali-earth oxide and $N_{4}$ is the fraction of $\mathrm{BO}_{4}$ units.

Multiplying this value by $V_{\mathrm{Fe}}$ we obtain the number of tetracoordinated borons localized around the radius of action of a $\mathrm{Fe}^{3+}$ ion, equal to 460 tetrahedra. Therefore, this is the maximum number of BOHC's possible to be contained inside this volume, since each hole is trapped near a $\mathrm{BO}_{4}$ tetrahedral unit. ${ }^{14}$ If the $\mathrm{Fe}^{3+}$ would be withdrawn from the center of the sphere of the killing action, each electron released by heating from a BEC would be caught, after penetrating the sphere, by an antibonding molecular orbital of the nearest of the BOHC's available in the volume. This is followed by a radiative recombination with the hole trapped in the $p-\pi$ molecular bonding orbital. ${ }^{14}$ Now, if a $\mathrm{Fe}^{3+}$ ion is present at the tetrahedral
$\mathrm{FeO}_{4}$ (or octahedral $\mathrm{FeO}_{6}$ ) molecular orbital, located at the central point, such a radiative recombination will be inhibited. We propose that this action is possible by means of a strongly delocalized $\mathrm{FeO}_{4}$ (or $\mathrm{FeO}_{6}$ ) molecular excited (antibonding) level very close to the conduction band whose action would be effective in the radius of $\sim 25 \AA$. Therefore, each of the 460 possible radiative processes is inhibited inside this volume and the detailed mechanism of the $e^{-}-h^{+}$recombination is explained with the help of some recent theories found in the literature.

In order to investigate if the $\mathrm{Fe}^{2+}$ ion is also effective as a TL emission killer, the samples $D_{2}$ and $G_{2}$ were considered, both nominally doped with $2 \times 10^{-2}$ at. $\%$ of $\mathrm{Fe}$, but with different $\left[\mathrm{Fe}^{2+}\right] /\left[\mathrm{Fe}_{\text {total }}\right]$ ratios. Assuming that the frequency factor of the dependence of the TL intensity with $\mathrm{Fe}$ concentration is independent of the ionization state of the Fe atom, Eq. (1) can be expressed as

$$
\begin{aligned}
A^{* *}=46.3 \exp \{ & -2.604 \times 10^{-19}\left[\mathrm{Fe}^{3+}\right] \\
- & \left.6.211 \times 10^{-19}\left[\mathrm{Fe}^{2+}\right]\right\} .
\end{aligned}
$$

Except for the sample $G_{3}$, where the $\left[\mathrm{Fe}^{2+}\right] /\left[\mathrm{Fe}_{\text {total }}\right]$ ratio was evaluated as $33 \%$, we assumed the value of $5 \%$ (Refs. 25 and 26) for all the samples, on the basis of our OA measurements of the samples $A_{1}, B_{1}$, and $B_{2}$ (Fig. 2 and Table II). The calculated values of $A^{*}$ [see Eq. (1)] and $A^{* *}$ [see Eq. (3)] may be compared with the experimental values of TL, shown in Table III. Both equations were satisfied for all the samples containing $5 \%$ of $\left[\mathrm{Fe}^{2+}\right]$, but only Eq. (3), where also the $\mathrm{Fe}^{2+}$ ions were included as the luminescence killers, was satisfied for all the samples, $G_{3}$ being also included. It is clear, therefore, that both $\mathrm{Fe}^{3+}$ and also $\mathrm{Fe}^{2+}$ ions are efficient luminescence killers.

Bishop and Taylor ${ }^{10}$ observed a PL quenching caused by iron impurity in chalcogenide glasses. They argued that the iron inhibits the luminescence by the introduction of nonradiative competitive centers, since any other light emission with different wavelength was not observed, as being associated with the killing of that luminescence. They suggested, based on the work of 
Robbins and Dean, ${ }^{28}$ that the nonradiative $e^{-}-h^{+}$recombination occurs by means of the energy transfer of the exciton recombination to the excited states of the $d$ band of a $\mathrm{Fe}$ ion. In the sequence, the excited ion relaxes nonradiatively with phonon emission. However, the central idea of their model is the prediction that a free electron or hole will not have sufficient electron-phonon coupling for the self-trapping necessary for the radiative recombination. On the other hand, the exciton has a strong coupling with the lattice, so that the nonradiative recombination with phonon emission is predominant. In chalcogenide glasses, the iron mostly appears in ferrous state, remaining only about $1 \%$ of $\mathrm{Fe}^{3+}$. Although the killing effect of iron was observed, the authors raised the question about which valence of $\mathrm{Fe}$ is the killer, or whether both are effective.

\section{CONCLUSIONS}

The $\mathrm{Fe}^{3+}$ and $\mathrm{Fe}^{2+}$ ions are efficient killers of the blue TL emission of the $e^{-}-h^{+}$recombination in $\mathrm{x}$ irradiated barium aluminoborate glasses, at temperatures between 77 and $300 \mathrm{~K}$. The quenching is total for Fe-doping concentrations above 0.1 at. \%. Each $\mathrm{Fe}^{3+}$ ion prevents any radiative $e^{-}-h^{+}$recombination within a radius of action of $25 \AA$.

The activation energy of electron untrapping from the BEC, $\Delta E=0.21 \mathrm{eV}$, is not very sensitive to glass composition variations of $\mathrm{B}_{2} \mathrm{O}_{3}$ and $\mathrm{Al}_{2} \mathrm{O}_{3}$ of about $10 \mathrm{~mol} \%$, suggesting that the electron traps are far apart, enough to prevent from interacting between themselves.

It was observed that the TL efficiency follows a decreasing exponential law with increasing $\mathrm{Fe}$ concentration. Assuming that the quenching process is due to a coherent capture of holes due to the strong multiphonon emission after the capture of an electron near $\mathrm{Fe}^{3+}$ (or
$\mathrm{Fe}^{2+}$ ), the observed TL intensity is in excellent agreement with the Sumi ${ }^{27}$ theory.

In this work it was shown that the $\mathrm{Fe}^{3+}$ and $\mathrm{Fe}^{2+}$ ions are efficient killers of the $e^{-}-h^{+}$recombination luminescence. An efficient quenching of luminescence has been reported by Bishop and Taylor ${ }^{10}$ in chalcogenide glasses, where the $\mathrm{Fe}^{2+}$ ion is the predominant one. Therefore, we conclude that the $e^{-}-h^{+}$recombination luminescence quenching is not sensitive to the particular oxidation state of the ion impurity. Also the interstitial $\mathrm{Fe}$ ions in the aluminoborate glasses cannot be ruled out as TL killers.

In the radius of action of $25 \AA$ around a substitutional $\mathrm{Fe}^{3+}$ ion in the site [see Fig. 5(a)] of a $\mathrm{B}_{2} \mathrm{O}_{7}$ doubletetrahedral structural unit, a $\mathrm{FeO}_{4}$ molecular-orbital antibonding state is strongly delocalized from mixing with the conduction-band states. An alternative site is the structure [see Fig. 5(b)] of $\mathrm{FeO}_{6}$ octahedron entwined with a $\mathrm{BO}_{4}$ tetrahedron $\left(\mathrm{FeBO}_{7}\right)$. The $e^{-}-h^{+}$radiative recombination is inhibited by the highly efficient competitive multiphonon emission process of coherent hole capture, which generates an exciton which interacts strongly with the lattice, producing additional multiphonon emission, leading to the nonradiative $e^{-}-h^{+}$recombination. As the change in the oxidation state of the $\mathrm{Fe}^{3+}$ ions is negligible in the process, we conclude that it plays a role of a catalyst, where a single ion accounts for the killing of a great number of $e^{-}-h^{+}$luminescent recombinations.

\section{ACKNOWLEDGMENTS}

This work was partly supported by grants from the Conselho Nacional de Desenvolvimento Científico (CNPq), the Fundação de Amparo à Pesquisa do Estado de São Paulo (FAPESP), and the Financiadora de Estudos e Projetos (FINEP).
${ }^{1}$ D. L. Griscom, J. Chem. Phys. 55, 1113 (1971).

${ }^{2}$ M. Schön, Z. Phys. 119, 470 (1942).

${ }^{3}$ H. A. Klasens, Nature (London) 158, 306 (1946).

${ }^{4}$ F. Urbach, A. Urbach, and M. Schwartz, J. Opt. Soc. Am. 37, 122 (1947).

${ }^{5}$ H. A. Klasens, W. Ramsden, and C. Quantie, J. Opt. Soc. Am. 38, 60 (1947).

${ }^{6}$ N. R. Nail, F. Urbach, and D. Pearlman, J. Opt. Soc. Am. 39, 690 (1949).

${ }^{7}$ R. H. Bube, S. Larach, and R. E. Shader, Phys. Rev. 92, 1135 (1953).

${ }^{8}$ C. A. Duboc, Brit. J. Appl. Phys., Suppl. 4, 107 (1955).

${ }^{9}$ H. A. Klasens, J. Phys. Chem. Solids 7, 1757 (1955).

${ }^{10}$ S. G. Bishop and P. C. Taylor, Philos. Mag. B 40, 483 (1979).

${ }^{11}$ R. D. Gold and L. R. Weisberg, Solid State Electron 7, 811 (1964).

${ }^{12}$ H. Sumi, J. Lumin. 40\&41, 76 (1988).

${ }^{13}$ W. M. Pontuschka, S. Isotani, and A. Piccini, J. Am. Ceram. Soc. 70, 59 (1987).

${ }^{14}$ D. L. Griscom, P. C. Taylor, D. A. Ware, and P. J. Bray, J. Chem. Phys. 48, 5158 (1968).

${ }^{15}$ E. J. Friebele and D. L. Griscom, Radiation Effects in Glass, Treatise on Materials Science and Technology Vol. 17, edited by M. Tomozawa and R. H. Doremus (Academic, New York, 1979), p. 257.

${ }^{16}$ M. I. T. Oliveira, S. H. Tatumi, N. O. Dantas, W. M. Pontuschka, and M. Sen (unpublished).

${ }^{17}$ T. Castner, Jr., G. S. Newell, W. C. Holton, and C. P. Slichter, J. Chem. Phys. 32, 668 (1960).

${ }^{18}$ D. L. Griscom, Borate Glass Structure, edited by L. D. Pye, V. D. Frechette, and N. J. Kreidl (Plenum, New York, 1978), p. 115.

${ }^{19}$ D. W. Moon, J. M. Aitken, R. K. Mac Crone, and G. S. Cieloszyk, Phys. Chem. Glasses 16, 91 (1975).

${ }^{20}$ R. Aasa, J. Chem. Phys. 52, 3919 (1970).

${ }^{21}$ C. G. Rouse and J. Williamson (unpublished).

${ }^{22}$ R. Chen, J. Mater. Science 11, 1521 (1976).

${ }^{23}$ P. Beekenkamp, Philips Res. Rep. Suppl., 4, 1 (1966).

${ }^{24}$ C. J. Ballhausen, Introduction to Ligand Field Theory, edited by Carl Johan, (McGraw-Hill, New York, 1962).

${ }^{25}$ T. K. Bansal and R. G. Mendiratta, J. Non-Cryst. Solids 86, 13 (1986).

${ }^{26}$ A. K. Bandyopadhyay, M. Ribes, F. Pernot, and J. Zarzycki, Phys. Chem. Glasses 23, 31 (1982).

${ }^{27}$ H. Sumi, Phys. Rev. B 27, 2374 (1983).

${ }^{28}$ D. J. Robbins and P. J. Dean, Adv. Phys. 27, 499 (1978). 